\title{
SPECIFIC CROP LOSSES DUE TO WEEDS
}

\author{
L. J. MATTHEWS
}

Ruakura Agricultural Research Centre M.A.F., Hamilton

\section{Summary}

Little factual data are available on crop losses due to weeds, but an assessment of the statistically sound weed control trials conducted by the Field Research Section of the Research Division, Ministry of Agriculture and Fisheries since 1964 show that weed losses are a major factor in crop production. From trials in six major crops the average yield increase obtained after the suppression of weeds was $140 \%$.

\section{INTRODUCTION}

The area and intensity of cropping is expanding in New Zealand. Weeds have always been an inherent problem, particularly where areas are cropped regularly. Cultivation encourages weed growth by breaking the dormancy of weed seeds, providing conditions suitable for successful germination and ensuring the burial of seed deposited on the ground surface.

Estimates of weed losses in New Zealand as a whole or for specific crops are not available except for the studies on wild oat (Avena spp.) undertaken by Allen and Smallridge (1972). Overseas estimates of crop losses vary widely, in USA for period 1951-60 weed losses were 8.5\% and for Canada the estimate was $15 \%$. These contrast markedly with estimates of $6-100 \%$ reported at the FAO Symposium on crop losses in 1967.

In this paper a selected range of crops was taken and the yield data assessed from 1964 to 1973 for the statistically sound trials conducted by the Field Research Section of the Research Division, Ministry of Agriculture and Fisheries. Trials labelled specifically "toierance triais" laid down on virtually weed-free sites were not included. The difference between the highest yield figure, i.e. the best herbicide treatment or combination of herbicide treatments, and the unweeded control are taken.

Wheat

\section{RESULTS}

Wheat was selected on the basis that it is intermediate in susceptibility to weed competition between barley and oats. In eight triais wild oats were the main contaminants, but as shown by Allen and Smallridge (1972) significant responses in yields are not recorded until the wild oat density is about 20 plants $/ \mathrm{m}^{2}$. In the trials considered the wild oat population varied from a low to a high density $\left(1.5\right.$ to $\left.35 / \mathrm{m}^{2}\right)$ and the overall increase in yield due to wild oat elimination or suppression was $18 \%$. In a further trial with very high density of wild oats $\left(433 / \mathrm{m}^{2}\right)$ the yield increase was $46 \%$. Where annual weeds were the main problem an average increase of $13 \%$ was recorded from three trials.

\section{Lucerne}

Lucerne is often sown with a cover crop due to the belief that it suffers little competition in the establishing stage. The increase in yields from four trials was $309 \%$ due solely to the control of broad-leaved species. 
For established lucerne the weeds are generally less competitive an increase of $51 \%$ being recorded from five trials. In a sixth trial control of single species - barley grass (Hordeum murinum) increased lucerne yield by $306 \%$. In a number of trials, however, the control of weeds reduced the total dry matter (i.e. lucerne plus weeds and grasses.)

Maize

In eight trials the yield increase due to the control of both broadleaved species and grasses either occurring alone or in combination was $152 \%$.

\section{Chou moellier}

This crop establishes quickly and is regarded as competitive owing to its upright growth and high yields. Nevertheless yields were increased by an average of $110 \%$ in four trials where weeds were controlled.

\section{Swedes}

Swedes are also a quick establishing crop and normally regarded as being fairly competitive, particularly when broadcast. The yield increase obtained in four trials was $126 \%$.

Peas

This crop is particularly sensitive to weed invasion for two reasons. There is a direct competitive effect of weeds and their presence produces conditions suitable for disease organisms. In eight trials weed control increased yield by an average of $137 \%$.

\section{DISCUSSION}

With the exception of peas the trials were sited in cropping districts and about half were located on farmers' properties. Half of the trials on peas were located at Hamilton, which is not a commercial pea growing area.

It may be assumed in general that the trial sites were selected on the basis that weeds would be a problem. While this is acknowldged it is also true that in most cases the herbicides utilised are not absolutely selective and that direct crop damage may have resulted from their use. This indicates that weeds in the trial areas considered may have been even more damaging than the results indicate.

Allen and Smallridge (1972) have shown clearly that wild oats depress wheat yields. The depression is normally small compared with other crops and this tends to confirm the belief that weeds in cereals are mainly troublesome at harvesting. In seed crops wild oats are not permitted as a contaminant and importing countries are placing an embargo on them as a contaminant in imported grain.

Meeklah et al (unpublished data) have shown the necessity to control weeds at the 1-leaf stage for maximum yields. The materials employed in the trials for the control of annual weeds were applied at the 3-leaf stage onwards, and hence are not fully indicative of possible yield increases due to weed suppression. It should be noted that many current recommendations are to apply herbicide at the 3-leaf to tillering stage and this is probably not the most suitable time.

Lucerne established under strong weed competition is not as productive in the first year as a clean stand, but it is not known how dong the loss of productivity persists. Similarly it is not known if the yield response to weed control obtained in the year of treatment of yiestablished stands carries over into succeeding years. Renovating such stands may result in a drop in total dry matter production, although the yield of lucerne may be increased significantly. 


\section{Economics of Weeds and Pests}

With maize broad-leaved weeds and/or grass weeds are sufficiently. competitive to cause complete crop failure. Under adverse conditions maize establishes slowly, but these conditions may be suitable for one ormore weed species to establish and dominate. Early sown crops are likely to have broad-leaved weeds as a problem, while in later crops warmzoned grasses may dominate. Once the maize has established weeds are of less significance.

The results with chou moellier and swedes were unexpected in view of the agronomic capabilities of these crops. In the chou moellier trial a single species, fathen (Chenopodium album complex) was the dominant weed. This species is very diverse in growth habit and is capable of beingcompetitive in most crops in the more temperate areas.

Peas are recognised as a crop susceptible to weed invasion. The yields: nevertheless are surprising in that truly selective herbicides are not available for this crop.

Where feasible hand-weeded or cultivated controls were employed as: a standard. In one trial only did the hand-weeded control give the same yields as the best herbicide treatment. In some trials the hand-weeded or cultivated control yields were less than those given by the best herbicide treatments, indicating the need for early weed control.

No data were obtained on how weeds reduced crop production orthe inter-relationship of diseases, insects, fertilisers, etc, and this should be the subject of further research.

\section{REFERENCE}

Allen, F. C. and Smallridge, T. J., 1972. Chemical control of wild oats alone and with broad-leaved weeds in wheat and barley. Proc. 25th Weed and Pest Control Conf: 192-198.

Proc. 27th N.Z. Weed and Pest Control Conf. 